\title{
A EDUCAÇÃO EM CIÊNCIAS E A INCLUSÃO DE ALUNOS COM DEFICIÊNCIA INTELECTUAL: ENTRAVES NO ENSINO DE FÍSICA
}

\author{
EDUCACIÓN EN CIENCIAS E INCLUSIÓN DE ESTUDIANTES CON \\ DISCAPACIDAD INTELECTUAL: INTERESES EN EDUCACIÓN FÍSICA
EDUCATION IN SCIENCES AND INCLUSION OF INTELLECTUAL DISABILITY STUDENTS: INTERESTS IN PHYSICAL EDUCATION

\author{
Mariangela DIAS ALVES ${ }^{1}$ \\ Paloma Alinne A. RODRIGUES ${ }^{2}$
}

\begin{abstract}
RESUMO: Este artigo apresenta resultados de uma pesquisa que teve o objetivo de investigar os obstáculos relacionados ao processo de inclusão educacional de alunos com Deficiência Intelectual (DI), na disciplina de Física, em uma escola regular. A investigação possuía uma abordagem qualitativa e configurava-se como um estudo de caso. Para a coleta dos dados foram realizadas duas entrevistas, uma com o professor do ensino regular e outra com a professora de apoio. Os dados revelaram que, devido à lacuna na formação do professor do ensino regular, os alunos não possuíam a oportunidade de construir conhecimentos relacionados aos conteúdos de Física. Além disso, os dois profissionais não desenvolviam, de forma efetiva, um trabalho colaborativo. Para finalizar, observou-se a existência de barreiras atitudinais, preconceitos e estigmas por parte de um dos docentes.
\end{abstract}

PALAVRAS-CHAVE: Inclusão. Ensino de Ciências. Formação de Professores.

RESUMEN: Este artículo presenta resultados de una investigación que tuvo el objetivo de investigar los obstáculos relacionados al proceso de inclusión educativa de alumnos con Discapacidad Intelectual (DI), en la disciplina de Física, en una escuela regular. La investigación tenía un enfoque cualitativo y se configuraba como un estudio de caso. Para la recolección de los datos se realizaron dos entrevistas, una con el profesor de enseñanza regular y otra con la profesora de apoyo. Los datos revelaron que debido a la brecha en la formación del profesor de enseñanza regular, los alumnos no tenían la oportunidad de construir conocimientos relacionados con los contenidos de Física. Además, los dos profesionales no desarrollaban, de forma efectiva, un trabajo colaborativo. Para finalizar, se observó la existencia de barreras actitudinales, preconceptos y estigmas por parte de uno de los docentes.

PALABRAS CLAVE: Inclusión. Enseñanza de Ciencias. Formación de profesores.

${ }^{1}$ Instituto Federal de Educação, Ciência e Tecnologia do Rio de Janeiro (IFRJ), Rio de Janeiro - RJ - Brasil. Acadêmica do curso de Terapia Ocupacional. ORCID: https://orcid.org/0000-0003-4077-2534. E-mail: mariangelacontato@hotmail.com

${ }^{2}$ Universidade Federal de Itajubá (UNIFEI), Itabira - MG - Brasil. Professora do Instituto de Física e Química (IFQ). Coordenadora do grupo de pesquisa "Núcleo de Estudos em Formação Docente, Tecnologias e Inclusão (NEFTI)”. ORCID: https://orcid.org/0000-0001-8186-1985. E-mail: palomaraap@unifei.edu.br

Doxa: Rev. Bras. Psico. e Educ., Araraquara, v. 21, n. 2, p. 374-386, jul/dez. 2019.

e-ISSN: 2594-8385 
ABSTRACT: This article presents results of a research that had the objective of investigating the obstacles related to the process of educational inclusion of students with Intellectual Disability (DI), in the discipline of Physics, in a regular school. The research had a qualitative approach and was configured as a case study. For the data collection, two interviews were carried out, one with the regular teacher and the other with the support teacher. The data revealed that due to the gap in the formation of the regular teacher, the students did not have the opportunity to build knowledge related to the contents of Physics. In addition, the two professionals did not effectively develop collaborative work. Finally, the existence of attitudinal barriers, prejudices and stigmata by one of the teachers was observed.

KEYWORDS: Inclusion. Science teaching. Teacher training.

\section{Introdução}

A inclusão de alunos com deficiência em classes regulares é um direito que está assegurado por lei. De acordo com a Declaração de Salamanca de 1994, "toda criança tem direito fundamental à educação, e deve ser dada a oportunidade de atingir e manter o nível adequado de aprendizagem". Na legislação brasileira, o Estatuto da Criança e do Adolescente de 1990, no artigo 53, I, determina que "A criança e o adolescente têm direito à educação, visando ao pleno desenvolvimento de sua pessoa, preparo para o exercício da cidadania e qualificação para o trabalho, assegurando-lhes: igualdade de condições para o acesso e permanência na escola". O artigo 54, III, institui que: "É dever do Estado assegurar à criança e ao adolescente: atendimento educacional especializado aos portadores de deficiência, preferencialmente na rede regular de ensino". Nota-se então que a Lei n. ${ }^{\circ} 8.069$, de 13 de julho de 1990, certifica de forma clara o direito à educação para pessoas que apresentem qualquer tipo de deficiência. A Lei de Diretrizes e Bases da Educação Nacional (BRASIL, 1996), além de garantir o acesso ao ensino em qualquer instituição pública, assegura, por meio do artigo 59, que o aluno com deficiência mantenha um nível de desenvolvimento e progresso por meio de "currículos, métodos, técnicas, recursos educativos e organização específicos, para atender às suas necessidades". Por sua vez, a versão atualizada, Lei n. ${ }^{\circ}$ 12.796/2013 (BRASIL, 2013), assegura a ampliação do atendimento educacional especializado aos estudantes público-alvo da Educação Especial na rede regular de ensino.

Nesse ínterim, é importante citar a Política Nacional de Educação Especial na Perspectiva da Educação Inclusiva (BRASIL, 2008) e a Lei Brasileira de Inclusão da Pessoa com Deficiência (BRASIL, 2015), as quais asseguram e promovem, ainda mais, os direitos dos sujeitos com deficiência nas esferas sociais e/ou educacionais. Diante do exposto, não restam dúvidas de que o sistema educacional público tem o dever não só de garantir o acesso, 
assim como todos os meios necessários para o pleno desenvolvimento da aprendizagem do aluno com deficiência.

No entanto, observa-se que, mesmo diante de todas as garantias legais, a inclusão escolar ainda é tida como um grande desafio. Um dos motivos é a formação dos professores para atuar em contextos inclusivos. No que concerne à formação inicial, estudos como o de Rodrigues (2015) revelam o temor de um grupo de licenciandos da área de Física, da Universidade Federal de Itajubá, para atuar com alunos com deficiência. Essa mesma situação foi contemplada na investigação de Vitaliano (2007) com um grupo de 178 professores atuantes em 13 cursos de licenciatura da Universidade Estadual de Londrina (UEL). Os dados revelaram que $84,2 \%$ dos participantes não possuíam conhecimentos suficientes para incluir alunos com deficiência, e apenas 7,8\% deles se sentiam aptos para atuar com essa clientela. Diante desse cenário, observa-se que há uma desarticulação entre o interior da universidade, responsável pela formação desse futuro professor, e a realidade da sala de aula da Educação Básica. Logo, para que haja efetivamente a democratização do ensino, torna-se necessário investir esforços na formação inicial. Sobre esse aspecto, Martins $(2009$, p. 110) alerta que "é importante que todos os docentes tenham conhecimentos sobre as necessidades de seus alunos, sobre como lidar com eles, como organizar o ensino e o currículo de maneira a atender as necessidades de todos". Diante da ausência de um embasamento teórico e prático, o licenciando, em especial das áreas relativas às Ciências, manterá a existência de práticas pedagógicas engessadas e segregacionistas em sala de aula. Com isso, o contexto escolar continuará a propiciar o fenômeno da pseudoinclusão, ou seja, ofertará uma inclusão "mascarada", na qual o aluno com deficiência frequenta a classe regular, mas não há um desenvolvimento de sua aprendizagem (PIMENTEL, 2012). Há que se entender que a inclusão escolar não se configura apenas como o acesso do aluno com deficiência ao ambiente escolar, mas também, como preconiza a lei, deve oferecer recursos físicos, pedagógicos e atitudinais que possibilitem ao aluno desenvolver suas habilidades e construir conhecimentos em sala de aula.

O processo de inclusão escolar suscita do professor uma formação permanente. No entanto, considera-se que essa formação deve ser centrada em situações que propiciem a construção de novos saberes, que possibilitem a criação de novas estratégias de ensino e principalmente que auxiliem o professor a refletir sobre a sua prática. Nóvoa (1997) afirma que estar em um processo de formação continuada “[...] implica um investimento pessoal, um trabalho livre e criativo sobre os percursos e os projetos próprios, com vista à construção de uma identidade, que é também uma identidade profissional” (NÓVOA, 1997, p. 25). Com base nisso, os cursos devem valorizar os conhecimentos advindos da prática e do caminhar 
pessoal do docente. É importante esclarecer que, dentro da proposta de escola inclusiva, o professor do ensino regular ainda pode contar com a parceria do professor do Atendimento Educacional Especializado (AEE). Por meio dessa colaboração, os dois professores se responsabilizam e compartilham do planejamento, execução e avaliação das atividades dos alunos com deficiência (MENDES et al., 2014). É importante esclarecer que o professor do AEE tem a atribuição de “[...] complementar/suplementar a formação do aluno com conhecimentos e recursos específicos que eliminam as barreiras as quais impedem ou limitam sua participação com autonomia e independência nas turmas comuns do ensino regular" (ROPOLI et al., 2010, [s.p.]). Esse trabalho em conjunto maximiza as ações do professor e melhora de forma significativa o aprendizado do aluno.

Segundo Ropoli et al. (2010, [s.p.]), "os professores do ensino regular e os da Educação Especial precisam se envolver para que seus objetivos específicos de ensino sejam alcançados, compartilhando um trabalho interdisciplinar e colaborativo". Mesmo que o docente não se sinta preparado para realizar as adaptações necessárias, pode e deve contar com o professor de apoio para que sejam traçados metas e objetivos para o desenvolvimento do aluno com deficiência. No entanto, mesmo com o auxílio do professor de apoio, o professor do ensino regular não se isenta da responsabilidade de planejar a aula, elaborar atividades e exercícios para os alunos com deficiência, exclusivamente para o professor de apoio. O professor do ensino regular é quem possui os conhecimentos dos conteúdos específicos para elaborar essas atividades, e o professor de apoio auxiliará o aluno a realizar as atividades, dentro das suas possibilidades. A nosso ver, essa ação ainda é mais significativa nas disciplinas relacionadas às Ciências, em especial ao Ensino de Física, que exige conhecimentos e técnicas considerados pelos alunos, sem deficiência, como complexas. Nesse ínterim, é importante destacar que há uma crescente produção de trabalhos sobre Ensino de Ciências em geral, incluindo o Ensino de Física. Eventos como o Encontro Nacional em Pesquisa em Educação em Ciência (Enpec) e o Simpósio Nacional de Ensino de Física (SNEF) proporcionam uma coletânea de pesquisas na área de Ciências. Entretanto, a investigação realizada por Siqueira e Rodrigues $(2016)^{3}$ revela a escassez de trabalhos relacionados à inclusão escolar e o ensino de Ciências nos periódicos da área.

Por outro lado, é imprescindível destacar que, assim como qualquer aluno, o sujeito com deficiência também tem o direito de construir conhecimentos sobre os conteúdos curriculares de Física. Neste trabalho, tem-se o intuito de chamar a atenção para os sujeitos com Deficiência Intelectual (DI), uma vez que “[...] os alunos com deficiência intelectual compõem o maior contingente dos alunos matriculados nas classes comuns e nos serviços de

${ }^{3}$ Os nomes dos autores foram omitidos tendo em vista a avaliação pelos pares. 
apoio [...]” (VELTRONE; MENDES, 2011, p. 414). A Associação Americana para as Atividades Intelectuais e Desenvolvimentais (AAIDD) esclarece que a DI “é caracterizada por significativas limitações do funcionamento intelectual e do comportamento adaptativo expresso em três domínios fundamentais: conceptual, social e prático (habilidades adaptativas) e manifesta-se antes dos 18 anos" (SCHALOCK et al., 2007, apud MORATO; SANTOS, 2012). A nosso ver, uma das vantagens de propiciar aos alunos com deficiência, em especial com DI, um ensino de Física inclusivo é que esse sujeito poderá construir conhecimentos para ingressar no Ensino Superior. No que concerne a esse nível de ensino, destaca-se a Lei n. ${ }^{\circ}$ 13.409/2016 (BRASIL, 2016), a qual determina as cotas nas universidades federais para pessoas com deficiência. Logo, observa-se mais uma vez a relevância da formação docente, assim como a presença do trabalho colaborativo para propiciar ao sujeito com deficiência um ensino de qualidade. Diante disso, este artigo tem o propósito de apresentar os resultados de uma pesquisa que visou verificar os desafios vivenciados por um professor de Física do Ensino Médio e o trabalho desenvolvido com a professora de apoio, de uma escola pública localizada no Sul de Minas Gerais, para promover a inclusão escolar de alunos com DI em sala de aula.

\section{Metodologia}

A pesquisa foi realizada em uma escola pública situada no Sul de Minas Gerais. Essa instituição foi escolhida por possuir um professor de Física efetivo, professora de apoio e alunos com DI incluídos na classe regular de ensino. A pesquisa constitui-se como um estudo de caso e possui uma abordagem qualitativa, a qual permite “[...] o contato direto e prolongado do pesquisador com o ambiente e a situação que está sendo investigada, via de regra por meio do trabalho intensivo de campo" (LUDKE; ANDRÉ, 1986, p. 11). Nessa abordagem metodológica são utilizadas diversas estratégias e instrumentos para coleta e análise dos dados. Neste estudo, utilizaram-se entrevistas semiestruturadas com o professor de Física e com a professora de apoio que atuavam na classe em que os alunos com DI estavam incluídos e observações em sala de aula. No entanto, neste trabalho serão destacados os resultados relativos às entrevistas semiestruturadas. Esse instrumento de coleta de dados foi escolhido por permitir que o entrevistador explore o momento da entrevista da melhor forma possível, elaborando questões que surgem ao longo da conversa. Essa ação possibilita ao entrevistador conduzir a entrevista de forma mais direcionada para o tema em questão, obtendo grande volume de informações para que os objetivos sejam alcançados (BONI; QUARESMA, 2005). 
$\mathrm{Na}$ entrevista, as questões foram previamente elaboradas, porém, no momento da sua realização, outras questões foram feitas ao entrevistado, permitindo assim o contexto de uma conversa informal. Os temas abordados no roteiro previamente definido foram: a formação inicial para a inclusão, a formação continuada, relacionamento entre o professor de física e a professora de apoio, adaptações curriculares dos conteúdos e as dificuldades encontradas por ambos os professores para promover a inclusão escolar dos alunos com DI. As entrevistas foram realizadas na própria escola ambiente desta pesquisa. Foram marcados com cada professor uma data e horário para sua realização. Eles foram registrados utilizando o recurso de gravação, em razão de esse método permitir "[...] contar com todo o material fornecido pelo informante, o que não ocorre com a utilização de anotações" (NOGUEIRA- MARTIS; BÓGUS, 2004, p. 51). Assim, foi possível analisar as principais dificuldades e barreiras que o professor de Física encontra para promover a inclusão escolar de alunos com DI, assim como a dinâmica da articulação do professor da disciplina e do professor de apoio, a fim de promover um desenvolvimento efetivo do aluno com deficiência. Para a discriminação dos sujeitos foi utilizada a sigla P1 para o professor de Física e P2 para a professora de apoio, a fim de preservar a identidade dos participantes da pesquisa.

Após a coleta dos dados, as entrevistas foram transcritas e, a partir disso, foi realizada uma análise textual discursiva (MORAES; GALIAZZI, 2006). Em seguida, foram elaboradas três categorias de análise: (a) a formação inicial e continuada para a inclusão - essa categoria pretendia analisar a formação inicial e continuada do professor de Física e da professora de apoio; (b) a dinâmica entre o professor de Física e a professora de apoio - objetivou-se analisar de que maneira o trabalho era realizado pelo professor da disciplina e pela professora de apoio, assim como as atribuições de cada um; e (c) as principais dificuldades que o professor de Física e a professora de apoio encontravam para promover a inclusão escolar de alunos com DI - nessa categoria os dados selecionados foram referentes às barreiras que existiam para os professores no processo da inclusão escolar.

\section{Resultados e discussão}

Os dados da primeira categoria "A formação inicial e continuada para a inclusão" revelam que o professor de Física (P1) não teve, em sua formação inicial, conhecimentos de cunho teórico e prático para atuar com alunos com deficiência. Isso fica claro no argumento a seguir: 
P1: "Não, não tinha esse... no meu tempo todo mundo era esperto! Não tinha INCLUSÃO! Nem sabia que existia isso fala a verdade pô cê!"”.

Como citado, há uma grande defasagem nos cursos de licenciatura no que diz respeito aos aspectos inclusivos. Por isso, é importante que o professor ao longo da sua carreira participe de cursos que abordem a temática da inclusão escolar. Ainda, durante a entrevista, quando questionado sobre sua formação, P1 citou que fez uma pós-graduação, como se verifica a seguir:

\section{P1: "Fiz pós em matemática".}

Já a professora de apoio (P2), após o término da graduação, ampliou seus conhecimentos por meio da formação continuada e demonstra em sua fala um crescente interesse pelo tema:

P2: “[...] fiz a pedagogia néh e fiz pós-graduação em educação especial. Depois disso continuei fazendo vários cursos... são no total dez cursos de 280 h. Todos os cursos que tem eu tô, eu procuro fazer".

A nosso ver, os dois argumentos revelam um dos entraves para potencializar o processo de inclusão escolar dos alunos com deficiência. A fala de P1 demonstra que nem sempre os professores estão dispostos a construir conhecimentos ou possuem interesse sobre a temática inclusiva. É importante citar que P1 possuía alunos com DI incluídos em sala de aula, logo era imprescindível buscar conhecimentos para ofertar um ensino de qualidade. No entanto, ao ser questionado se a escola onde atuava ofereceu algum curso de formação continuada que abordasse a temática de inclusão, P1 foi enfático:

P1: "Olha, não chegou a oferecer, mas se chegar também não tenho interesse. Não tenho interesse entendeu... Vô fazer de tudo pra não precisar ir... Infelizmente porque não concordo com esse sistema".

A fala de P1 revela a postura de um professor que não acredita na inclusão de alunos com deficiência. Dessa forma, o processo de ensino e aprendizagem desses alunos torna-se muito mais difícil em virtude da barreira criada pela própria atuação docente. Com isso, os alunos com deficiência continuam à margem e não têm a oportunidade de ter uma educação de qualidade e desenvolver suas potencialidades. Por outro lado, considera-se que a escola deve propiciar aos professores momentos de formação para desconstruir esse tipo de visão e, até mesmo, evitar a proliferação do preconceito.

Com a segunda categoria de análise, "A dinâmica entre o professor de Física e a professora de apoio", foi possível verificar como era desenvolvido o trabalho desses dois

4 As falas aqui transcritas não sofreram nenhuma modificação com o objetivo de assegurar a fidedignidade dos fatos. Além disso, as letras maiúsculas indicam uma entonação enfática do professor sujeito da pesquisa. 
profissionais. Desse modo, quando questionados se eles dialogavam sobre o planejamento das aulas e das atividades para os alunos com deficiência, obtivemos as seguintes respostas:

P1: "[...] é essa conversa tem entendeu, isso tem entendeu, a gente faz, a atividade que eu faço assim é mais leitura entendeu leitura, pô eles pra escrever algum texto entendeu, mas mesmo assim ainda têm dificuldade né, porque eles também têm dificuldade motora".

P2: "Sempre teve, com todos, não é só com ele não. Todos nós, todos eu tenho esse relacionamento em tá adaptando até mesmo ajudando eles porque têm pessoas que têm professores que têm dificuldade em atuar com o AEE, não é todos que têm facilidade têm uns que têm dificuldade néh".

A partir das falas, verifica-se que há uma dinâmica de trabalho entre os dois profissionais. Essa ação é muito importante para que os alunos com deficiência possam participar das atividades que estão sendo propostas para a turma. Contudo, quando P1 é questionado com relação às adaptações curriculares que precisam ser realizadas e de que forma ele busca fazer isso com $\mathrm{P} 2$, ele responde que não tem um tempo reservado para essa ação. Além disso, pondera que esse trabalho é apenas responsabilidade de P2:

P1: "Não porque o Estado não propicia esse tempo pra gente, entendeu, então a gente não usa nenhuma hora extra, nenhuma coisa extra não entendeu, aí vai da vontade às vezes da professora de apoio em querer fazer entendeu, que tá a cargo disso, mas a gente mesmo não tem nada preparado não entendeu, deixa mais por conta dela mesmo. Deixo a cargo dela fazer entendeu, ai ela me passa depois entendeu".

Ao longo das falas do professor $\mathrm{P} 1$, observa-se que ele é muito resistente à inclusão, o que cria uma grande barreira no aprendizado e desenvolvimento dos alunos com deficiência. Por outro lado, o docente que atua no contexto inclusivo precisa sair da zona de conforto e adaptar-se às diferentes situações que podem ser apresentadas no contexto da sala de aula.

$\mathrm{O}$ argumento de P1 ainda revela que as adaptações curriculares ficam a cargo de P2. Como citado anteriormente, essa postura não é coerente com a proposta do ensino colaborativo, porque o professor de apoio está dentro da sala de aula para auxiliar o aluno com deficiência; esse profissional não possui conhecimentos específicos da disciplina de Física. Portanto, quem deve fazer as adaptações curriculares e propor novas abordagens sempre deve ser o professor da disciplina. No tocante a isso, P2 diz:

P2: “[...] o professor e logicamente sempre estou junto néh com a minha pequena como diz a minha pequena experiência néh eu acho que a cada dia a gente aprende um pouquinho então a gente troca ideias, chegamos num bom senso néh muitas vezes ah se a gente for por esse lado, não vamos adaptar desse jeito e no fim no final dá tudo certo... a gente forma pedagoga a gente não forma física, química, biologia néh a gente vai querendo aprender $[\ldots] "$. 
É preciso compreender que as ações do professor de apoio são diferentes das atividades do professor do ensino regular. Desse modo, ao questionar como era a atuação de P2, a docente explicou que ela faz:

P2: "Tudo o que está ao meu alcance, acompanho eu ficou sentada com elas eu sento no meio e uma de cada lado... cê tem que tá muito preparada porque não é só cê sentar do ladinho delas e ficar. NÃO! Você tem que ajudá-la a crescer intelectualmente néh. Elas precisam CRESCER! Então elas têm o potencial delas, elas aprendem! Tá. Dentro da possibilidade delas... do todo todo apoio relacionado a todos os conteúdos em relação a trabalho os trabalhos de casa, o trabalho feito na sala de aula éeh a matéria, quando não vem coloca a matéria em dia tá então o tempo todo tá ali junto com elas em todos os sentidos ééh se sente mal eu desloco e tiro, ligo pro pai, pra mãe, pro responsável vim buscar então tem todo esse amparo $[\ldots]$...

A partir do exposto, verifica-se que o professor de apoio é um profissional essencial quando se aborda a inclusão escolar, uma vez que ele pode potencializar a equiparação de oportunidades para que o aluno com deficiência possa participar das atividades propostas em sala de aula. Logo, o professor de apoio é tido como um facilitador do processo de ensino e aprendizagem e, por isso, os conhecimentos específicos não podem ficar sob sua responsabilidade.

A última categoria de análise permitiu-nos investigar "as principais dificuldades que o professor de Física e a professora de apoio encontravam para promover a inclusão educacional de alunos com DI". Para isso, algumas questões abordaram a dinâmica da sala de aula. Inicialmente, questionou-se sobre a participação dos alunos com deficiência nas aulas. Desse modo, os professores citaram que:

P1: "não é igual aos outros alunos, eles têm o acompanhamento da professora de apoio néh entendeu e eles têm atividade extraclasse. Eles não têm como, eles não conseguem acompanhar a aula!".

P2: "É ele eles eram bem ouvintes néh, porque não tinha uma uma assim uma dinâmica diversificada".

As falas revelam que os alunos com deficiência não tinham a oportunidade de construir conhecimentos por meio do desenvolvimento das atividades. A nosso ver, os depoimentos demonstram que não havia uma adaptação curricular dos conteúdos trabalhados, mas sim uma pseudoinclusão. Finalmente, quando questionados sobre as dificuldades vivenciadas, encontramos posicionamentos divergentes:

P1: "Todas as dificuldades porque eu não tô preparado pra lidar com alunos assim! E e a minha matéria não... até agora não achou um jeito de trabalhar com isso aí, com esses alunos entendeu, não tem entendeu, ééé o nível de dificuldade deles é muito grande entendeu, então não tem como... 
eles aprenderem a matéria... sem ser alguma coisa assim mais prática entendeu. Acho queee tão no local errado, essa é minha opinião né, entendeu... Eles não vão aprender física! Os normais não conseguem aprender física como é que eu vou fazer com o deficiente aprender física! É muito complicado entendeu! Do jeito que é dado assim na sala de aula no quadro com conta não tem jeito ué, impossivel! Por mais boa vontade que se tenha! Além de trabalhar com gente especial, além de você ter que ter o dom né de querer trabalhar entendeu você tem que ter condições e a gente não tem essas condições, o Estado não propicia isso aí entendeu. Não tem né, pô eles aqui é fácil, pô na sala de aula é fácil, mas e aí? Né?".

$\mathrm{O}$ argumento de $\mathrm{P} 1$ demonstra a existência do preconceito contra o processo inclusivo. No entanto, entende-se que essa não pode ser a postura de um profissional da área de Educação. Quando o docente cria uma barreira atitudinal, nenhum aluno terá a possibilidade de desenvolver suas potencialidades e autonomia, independentemente de ter deficiência ou não. Isso fica claro quando ele argumenta que "[...] Os normais não conseguem aprender Física como é que eu vou fazer com o deficiente aprender física! [...]”.

Por meio dessa fala observa-se que para ele os alunos já estão fadados ao fracasso e não são capazes de ter um aprendizado significativo. Por outro lado, a nosso ver, isso também revela que P1 precisa mudar a prática pedagógica para que todos os alunos possam construir os conhecimentos relacionados aos conteúdos de Física. É importante lembrar que o processo de aprendizagem está intimamente articulado com o método de ensino! Já o argumento de P2 demonstra uma visão mais otimista com relação à inclusão escolar:

P2: "Não, dificuldade não é a palavra correta não, eu acho que a dificuldade que a gente encontra é estar ali atualizando né você tem que tá constantemente atualizando porque todos eles têm um potencial, todos têm um potencial, basta você fazer um bom trabalho, você fazendo um bom trabalho você tem resultado, então não existe dificuldade existe aceitação néh se eu aceito aquilo que eu tô atuando vou melhorar pra ampliar melhor... cada um é uma realidade néh não são iguais e a gente aprende muito. Nãooo, volto a dizer o professor ele veste a camisa, o AEE ele grava muito aquilo que ele visualiza o que ele mesmo éh visualiza memoriza é é e pega... eles verem eles gravam você entendeu agora você falar uma coisa distante da realidade deles aí fica difícil pra melhor pra memorizar. É a maneira de ser dado. Tanto é que a inclusão tá aí néh se for pensa assim então não teria!”.

O comentário de P2 demonstra que, para atuar em uma perspectiva inclusiva, o professor necessita se envolver. Portanto, ele realmente incluirá o aluno com deficiência no contexto escolar. Ela ainda salienta que o professor da disciplina deve construir novas estratégias e "vestir a camisa". Outro aspecto apontado é a questão da formação, a qual salienta que é preciso buscar, sempre, conhecimentos para explorar as potencialidades de cada aluno. 


\section{Considerações finais}

A partir do exposto, observa-se que a formação inicial e continuada é essencial para o processo de inclusão de alunos com deficiência em salas de aulas regulares. A ausência de subsídios, teóricos e práticos, durante a graduação configura-se como um dos entraves do processo de inclusão. Por isso, a formação continuada entra como peça-chave para que o docente construa mais conhecimento para atender de forma inclusiva os alunos da sala de aula, contemplando, assim, a heterogeneidade do ambiente.

Além disso, a inclusão dos alunos com deficiência suscita a presença de um trabalho colaborativo entre o professor do ensino regular, em especial o de Física, e o professor de apoio. Essa dinâmica maximiza as ações do professor e permite que haja metas e caminhos em comum traçados por ambos os profissionais, a fim de que, dessa forma, o desenvolvimento dos alunos seja muito mais efetivo. Por outro lado, se o professor do ensino regular se isentar da responsabilidade, surge mais um entrave no processo de inclusão escolar. Considera-se também a necessidade de as instituições de ensino promoverem ações de formação para propiciar aos professores conhecimentos teóricos e práticos. Tal ação pode estimular a reflexão sobre a prática pedagógica e evitar a proliferação de preconceitos e estigmas dentro do contexto escolar.

Para finalizar, considera-se que o professor necessita explorar as potencialidades de seus alunos e valorizar as diferenças que compõem o universo da sala de aula, pois, independentemente das condições físicas, sensoriais e intelectuais, todos possuem o direito de conhecer os conteúdos relacionados às Ciências e, em especial, os que compõem a disciplina de Física.

\section{REFERÊNCIAS}

BELO, C.; CABRAL, L.; CARIDADE, H.; SOUSA, R. Deficiência intelectual: terminologia e conceptualização. Disponível em: http://www.madeiraedu.pt/Portals/7/pdf/revista_diversidades/revistadiversidades_22.pdf\#page=4. Acesso em: 7 jun. 2019.

BONI, V.; QUARESMA, J.S. Aprendendo a entrevistar: como fazer entrevistas em Ciências Sociais. Revista Eletrônica dos Pós-Graduandos em Sociologia Política da UFSC, v. 2, n. 1, jan./jul. 2005, p. 68-80. Disponível em:

https://periodicos.ufsc.br/index.php/emtese/article/view/18027/16976. Acesso em: 7 jun. 2019.

BRASIL. Lei n. ${ }^{\circ}$ 8.069, de 13 de julho de 1990. Disponível em:

http://www.planalto.gov.br/ccivil_03/leis/18069.htm. Acesso em: 7 jun. 2019. 
BRASIL. Declaração de Salamanca, 1994. Disponível em:

http://portal.mec.gov.br/seesp/arquivos/pdf/salamanca.pdf. Acesso em: 7 jun. 2019.

BRASIL. Lei n. ${ }^{\circ}$ 9.394, de 20 de dezembro de 1996. Disponível em:

http://portal.mec.gov.br/seesp/arquivos/pdf/lei9394_ldbn2.pdf. Acesso em: 7 jun. 2019.

BRASIL. Ministério da Educação. Secretaria de Educação Especial (SEESP). Política

Nacional de Educação Especial na Perspectiva da Educação Inclusiva. Brasília:

MEC/SEESP, 2008.

BRASIL. Decreto n. ${ }^{0}$ 7.611, de 17 de novembro de 2011. Disponível em

http://www.planalto.gov.br/ccivil_03/_Ato2011-2014/2011/Decreto/D7611.htm\#art11.

Acesso em: 7 jun. 2019.

BRASIL. Lei n. ${ }^{\circ}$ 12.796, de 4 de abril de 2013. Disponível em:

http://www.planalto.gov.br/ccivil_03/_ato2011-2014/2013/lei/l12796.htm. Acesso em: 7 jun. 2019.

BRASIL. Lei n. ${ }^{\mathbf{1}}$ 13.146, de 6 de julho de 2015. Disponível em:

http://www.planalto.gov.br/ccivil_03/_ato2015-2018/2015/lei/113146.htm. Acesso em: 7 jun. 2019.

BRASIL. Lei no 13.409, de 28 de dezembro de 2016. Disponível em:

http://www.planalto.gov.br/ccivil_03/_ato2015-2018/2016/lei/L13409.htm. Acesso em: 7 jun. 2019.

COSTA, R. P. M. Educação especial: aspectos conceituais e emergentes. São Carlos: EdUFSCar, 2009

LÜDKE, M.; ANDRÉ, M. E. D. A. Pesquisa em educação: abordagens qualitativas, temas básicos de educação e ensino. São Paulo: Editora Pedagógica e Universitária, 1986.

MARTINS, L. A. R. Um olhar para a formação docente na perspectiva da educação inclusiva. In: MARQUEZINE, M. C.; MANZINI, E. J.; BUSTO, R. M.; TANAKA, E. D. O.; FUJISAWA, D. S. (Org.). Políticas públicas e formação de recursos humanos em educação especial. Londrina: ABPEE, 2009. p. 107-118.

MENDES, E. G.; VILARONGA, C. A.; ZERBATO, A. P. O ensino colaborativo como apoio à inclusão escolar: unindo esforços entre a educação comum e especial. São Carlos: UFSCar, 2014.

MIRANDA, G. T.; GALVÃO FILHO, T. A. O professor e a educação inclusiva: formação, práticas e lugares. Salvador: EDUFBA, 2012.

MORAES, R.; GALIAZZI, M. C. Análise textual discursiva: processo reconstrutivo de múltiplas faces. Ciência \& Educação, Bauru, v. 12, n. 1, p. 117-128, 2006.

NOGUEIRA-MARTINS, M.C.F.; BÓGUS, C.M. Considerações sobre a metodologia como recurso para o estudo humanização em saúde. Saúde e Sociedade, v. 13, n.3, p.44-57, set-dez 2004

NÓVOA, A. (Coord.). Os professores e a sua formação. Tradução Graça Cunha, Cândida Hespanha, Conceição Afonso e José Antonio Sousa Tavares. Lisboa: Dom Quixote 1997. 
PIMENTEL. Susana C. Formação de professores para a inclusão: saberes necessários e percursos formativos. In: MIRANDA, Theresinha G. GALVÃO FILHO. Teófilo A. (Orgs). $\mathbf{O}$ professor e a educação inclusiva: formação, práticas e lugares. Salvador: EDUFBA, 2012

\section{RODRIGUES, P. A. A. A perspectiva dos futuros professores de Física para atuar em} aulas inclusivas: sentidos e desafios na formação inicial. 2015. Disponível em: http://www.abrapecnet.org.br/enpec/x-enpec/anais2015/lista_area_12.htm. Acesso em: 7 jun. 2019.

ROPOLI, A. E.; MANTOAN, E. M. T.; SANTOS, T. C. M. T.; MACHADO, R. A educação especial na perspectiva da inclusão escolar: a escola comum inclusiva. 2010. Disponível em: http://www.acervodigital.unesp.br/handle/123456789/25849?locale=pt_BR. Acesso em: 7 jun. 2019.

SANT'ANA, M. I. Educação inclusiva: concepções de professores e diretores. Disponível em: http://www.scielo.br/pdf/pe/v10n2/v10n2a09.pdf. Acesso em: 7 jun. 2019.

SANTOS, S; MORATO, P. Acertando o passo! Falar de deficiência mental é um erro: deve falar-se de dificuldade intelectual e desenvolvimental (DID). Por quê? Rev. Bras. Ed. Esp. Marília, v. 18, n. 1, p. 3-16, Jan/Mar. 2012.

SIQUEIRA, A. M.; RODRIGUES, P. A. A. Análise das pesquisas de educação inclusiva em periódicos relacionados ao ensino de ciências. In: VII CONGRESSO BRASILEIRO DE EDUCAÇÃO ESPECIAL E O X ENCONTRO NACIONAL DE PESQUISADORES DA EDUCAÇÃO ESPECIAL (X ENPEE), 2016, São Carlos. VII Congresso Brasileiro de Educação Especial, 2016. p. 1-14.

VELTRONE, A. A.; MENDES, G. E. Descrição das propostas do Ministério da Educação na Avaliação da Deficiência Intelectual. 2011. Disponível em:

http://www.scielo.br/pdf/paideia/v21n50/14.pdf. Acesso em: 7 jun. 2019.

VITALIANO, R.C. Análise da necessidade de preparação pedagógica de professores de cursos de licenciatura para inclusão de alunos com necessidades educacionais especiais, Revista Brasileira de Educação Especial, Marília, v. 13, n. 3, p. 399-414, set./dez. 2007.

\section{Como referenciar este artigo}

ALVES, Mariangela Dias e RODRIGUES, Paloma Alinne A. A educação em ciências e a inclusão de alunos com deficiência intelectual: entraves no ensino de física. Doxa: Rev. Bras. Psico. e Educ., Araraquara, v. 21, n. 2, p. 374-386, jul./dez. 2019. e-ISSN: 2594-8385. DOI: https://doi.org/10.30715/doxa.v21i2.13184

Submetido em: 20/02/2019

Aprovado em: 20/07/2019

Publicado em: 01/08/2019 